Gut, 1973, 14, 885-890

\title{
Bile salt metabolism in patients with gallstones in functioning gallbladders
}

\author{
E. W. POMARE AND K. W. HEATON
}

From the University Department of Medicine, Royal Infirmary, Bristol

SUMMARY Isotopic bile salt studies were carried out in eight middle-aged women with radiolucent gallstones in functioning gallbladders and in 10 matched controls. In the gallstone patients the size of the bile salt pool was reduced by $37 \%$ to $1.79 \mathrm{~g}$, but there was considerable overlap with the normal subjects. The cholate and chenodeoxycholate pools were reduced, but the deoxycholate pool was normal in size. There were changes in bile salt metabolism which resembled those found after cholecystectomy but were less marked. This suggests that in gallstone disease the storage capacity of the gallbladder is impaired. This may contribute to the small bile salt pool, but it is unlikely to be the sole or even the major cause.

The tendency to form the common cholesterol-rich gallstone depends upon the liver secreting bile which contains an excess of cholesterol in relation to the solubilizers of cholesterol, namely, phospholipid and bile salts (Small, 1970). Bile salts play a central role because their secretion determines the secretion of phospholipid (Bell, Vlahcevic, and Swell, 1971). Failure of bile salt secretion is generally regarded as a major factor in making bile 'lithogenic', that is, supersaturated with cholesterol (Redinger and Small, 1972), though excessive cholesterol secretion is likely to play a part, at least in obese subjects (Grundy, Metzger, and Adler, 1972). The main factor determining the concentration of bile salt in hepatic bile is the size of the circulating pool. In 1970, Vlahcevic, Bell, Buhac, Farrar, and Swell reported that the bile salt pool was reduced to little more than half its normal size in men who had gallstones in radiologically functioning gallbladders. This important finding has been confirmed in American Indian women and men (Vlahcevic, Bell, Gregory, Buker, Juttijudata, and Swell, 1972; Bell, McCormick, Gregory, Law, Vlahcevic, and Swell, 1972) but not in non-Indian women nor in patients outside the United States. The diminution of the bile salt pool is probably due to a reduction in the pools of both primary bile salts, cholate and chenodeoxycholate (Vlahcevic et al, 1970), though it has been claimed that only the chenodeoxycholate pool is reduced (Danzinger, Hofmann, Schoenfield, Berngruber, Szczepanik, and Klein, 1971). The pool size of the secondary bile salt, deoxycholate, was not signifi- cantly altered in the studies of Vlahcevic et al (1970, 1972) or of Bell et al (1972). In their more recent publications these investgators showed that the daily synthesis of primary bile salt is normal, and that the turnover rates of the two primary bile salt pools are increased.

It was suggested by Vlahcevic et al (1970) that reduction of the bile salt pool precedes gallstone formation and probably causes it. This hypothesis was supported by the finding that American Indians who secreted lithogenic bile had reduced bile salt pools, even if they had no gallstones (Vlahcevic et al, 1972; Bell et al, 1972). It is commonly accepted that such subjects are in a pregallstone state, though it has not yet been shown that subjects characterized in this way go on to suffer a high incidence of gallstones. The cause of the small bile salt pool has not been discovered. However, failure to maintain a normal size pool in the absence of excessive bile salt loss strongly suggests that the hepatic synthetic mechanism is inhibited (Vlahcevic et al, 1972; Heaton, 1973). In a previous paper (Pomare and Heaton, 1973) we have shown that the size of the bile salt pool, and also its metabolism and composition, are strongly influenced by the storage function of the gallbladder. In the present study, we have used the techniques of that paper to re-examine the altered bile salt metabolism of patients with radiolucent gallstones. Such stones are very likely to be rich in cholesterol (Dowling, 1973).

\section{Subjects and Methods}

The subjects studied were eight women aged 35-55. 
years (mean 51 years), who had been found by oral cholecystography to have radiolucent stones, occupying but not filling gallbladders which concentrated and contracted normally. They had not suffered biliary pain in recent weeks and had never been jaundiced. Also studied was a control group of 10 healthy women aged 41-58 years (mean 51 years), in whom oral cholecystography was entirely normal. All subjects were eating a normal, unrestricted diet.

The methods used to study the kinetics of taurocholate were identical to those in a previous paper (Pomare and Heaton, 1973) Cholecystokininpancreozymin was given to both groups to stimulate bile flow. The radioactive bile salt administered to the gallstone patients was sodium taurocholate-24-14 $\mathrm{C}$ in seven cases and deoxycholic acid-24-14 $\mathrm{C}$ in one case. All controls received labelled taurocholate. The methods described by Pomare and Heaton (1973) were also used to study the recirculation of labelled metabolites of taurocholate, to measure the relative proportions of the three main bile salts (cholate, chenodeoxycholate, and deoxycholate), to measure the $\mathrm{G} / \mathrm{T}$ ratio, and to calculate the size of the total and component bile salt pools. Statistical significance of differences between the two groups was tested by Student's $t$ test and regression analysis.

\section{Results}

\section{KINETICS OF TAUROCHOLATE- $24-14 \mathrm{C}$}

Figure 1 shows the half-life of radioactive taurocholate in the two groups studied. The mean values $( \pm \mathrm{SD}$ ) were $1.65 \pm 0.61$ days in the control group and $1.16 \pm 0.43$ days in the gallstone group. The difference is of borderline significance $(t=1.7481$, $P \bumpeq 0.05$ ).

The pool size of taurocholate was significantly smaller in the gallstone group (fig 2), the mean values ( \pm SD) being $190 \pm 54 \mathrm{mg}$ compared with $358 \pm 177 \mathrm{mg}$ in the controls $(P<0.025)$. There was no difference in the daily synthesis of taurocholate in the two groups, the mean values ( \pm SD) being $149 \pm 47 \mathrm{mg}$ in the controls and $130 \pm 38 \mathrm{mg}$ in the gallstone subjects (fig 3 ).

In the one gallstone subject given radioactive deoxycholic acid the half-life of this bile acid was 3.67 days, the pool size $0.48 \mathrm{~g}$, and the production rate $91 \mathrm{mg} /$ day.

\section{COMPOSITION AND SIZE OF THE BILE SALT POOL}

The relative proportions of cholate, chenodeoxycholate, and deoxycholate in the bile salt pool are shown in figure 4 . The proportion of cholate was similar in gallstone subjects and controls, the mean value $( \pm S D)$ being $38.1 \pm 5.9 \%$ compared with $39.1 \pm 5.5 \%$ in the controls. Similarly, there was no significant difference in the proportion of chenodeoxycholate, which was $27.9 \pm 7.9 \%$ in the gallstone group compared with $34 \cdot 1 \pm 6.8 \%$ in the controls, nor in the proportion of deoxycholate, which was $34.0 \pm 10.3 \%$ in the gallstone group and $26.8 \pm 9 \cdot 4 \%$ in the controls.

The $G / T$ ratio was similar in the two groups, being on average $2.33 \pm 0.63$ in the controls and $2.56 \pm$ 0.94 in the gallstone subjects.

The calculated size of the component bile salt pools is shown in figure 5 . In the gallstone subjects the cholate pool was reduced by $39 \%$, the mean ( \pm

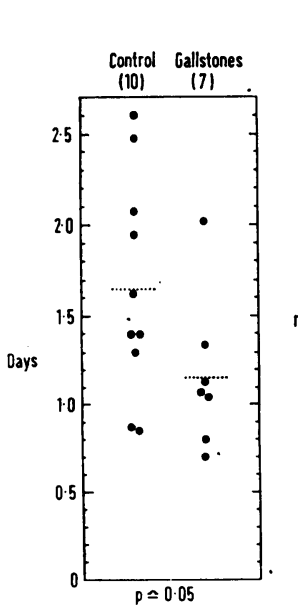

Fig 1'

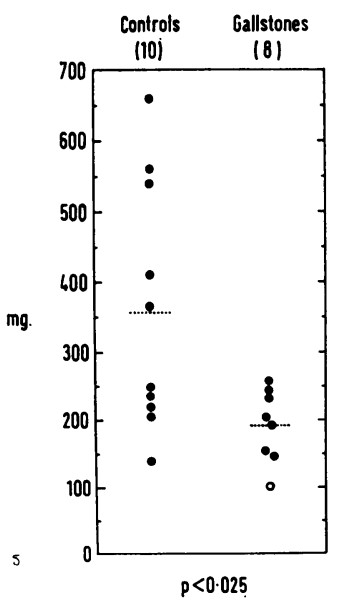

Fig 2

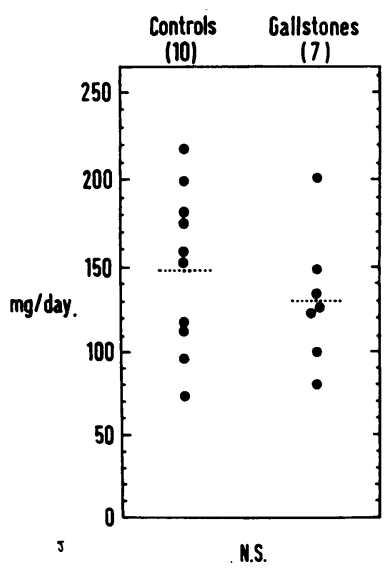

Fig 3
Fig 1 The half-life of taurocholate in days in the two groups studied.

Fig 2 The pool size of taurocholate in the two groups. The open circle represents a value calculated from a deoxycholic acid-24-14 C study.

Fig 3 The daily synthesis of taurocholate in the two groups. 


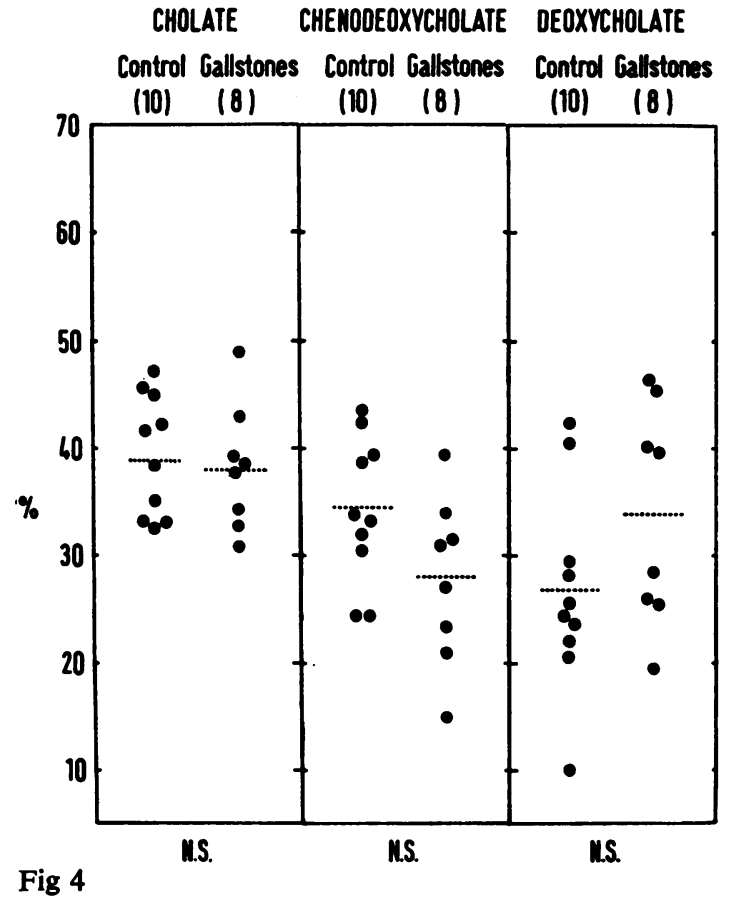

SD) being $0.69 \pm 0.20 \mathrm{~g}$ compared with $1.13 \pm 0.46 \mathrm{~g}$ in the controls $(P<0.025)$. The chenodeoxycholate pool was reduced by $48 \%$, being $0.51 \pm 0.20 \mathrm{~g}$ compared with $0.98 \pm 0.40 \mathrm{~g}$ in the controls $(\mathrm{P}<$ $0.01)$. However, the deoxycholate pool was not

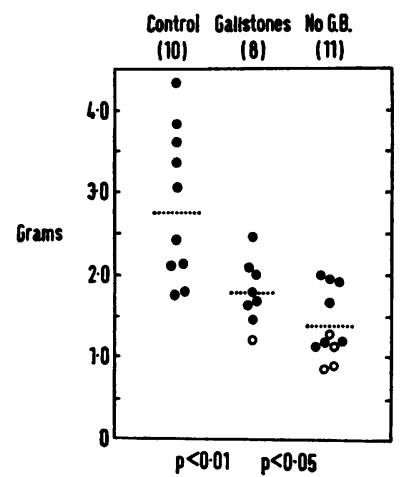

Fig 6

significantly different in the two groups (mean $0.59 \pm 0.18 \mathrm{~g}$ in the gallstone group and $0.72 \pm$ $0.26 \mathrm{~g}$ in the controls).

The total bile salt pool was significantly reduced in the gallstone subjects, the mean $( \pm$ SD) being $1.79 \pm 0.39 \mathrm{~g}$ compared with $2.83 \pm 0.91 \mathrm{~g}$ in the controls $(P<0.01)$. However, the total pool of gallstone patients was significantly larger than that of a group of 11 subjects who had undergone cholecystectomy for gallstones $(P<0.05)$ (fig 6). The latter data are extracted from a previous paper (Pomare and Heaton, 1973).

\section{RECIRCULATION OF LABELLED METABOLITES OF TAUROCHOLATE-24-14 C}

The proportion of bile radioactivity in all metabolites

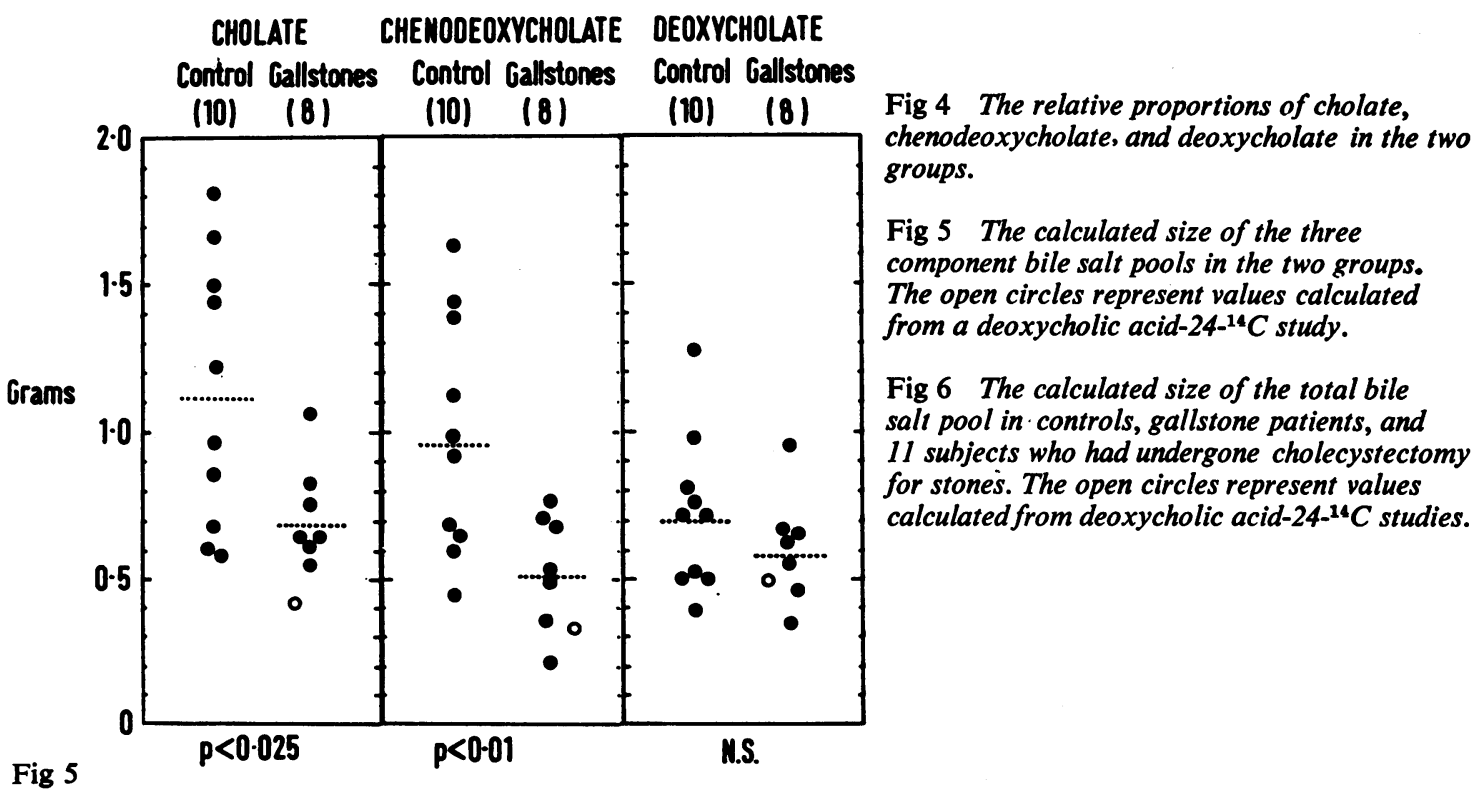

Fig 5 


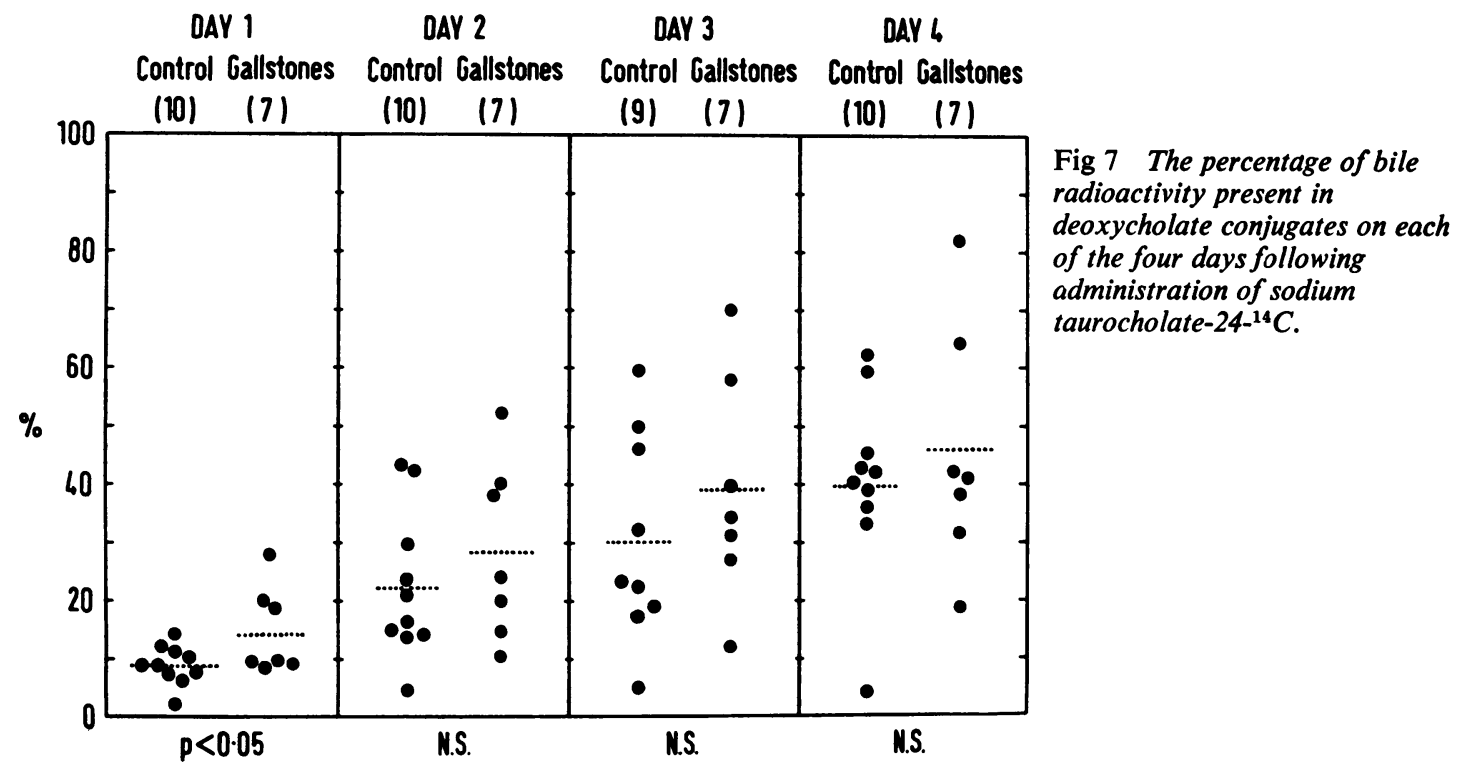

of taurocholate (glycocholate, glycodeoxycholate, and taurodeoxycholate) was slightly higher in the gallstone patients on all four study days, but the difference from the control group was not statistically significant on any one day. The mean values for the four days were, in the control group, $23.1 \%, 47 \cdot 6 \%$, $63.1 \%$, and $68.5 \%$, and in the gallstone group, $36.6 \%, 57.4 \%, 70.4 \%$, and $77.3 \%$.

The proportion of bile radioactivity in deoxycholate conjugates was slightly higher on all four days in the gallstone group, but significantly so on day 1 only (fig 7). The mean values ( \pm SD) for each of the four days were $14.1 \pm 7.7 \%, 28.6 \pm$ $15.4 \%, 38.9 \pm 19.7 \%$, and $46.2 \pm 22.2 \%$ respectively, compared with $8 \cdot 8 \pm 3.3 \%, 22 \cdot 4 \pm 12 \cdot 5 \%$, $30 \cdot 2 \pm 17 \cdot 8 \%$, and $40 \cdot 2 \pm 16.0 \%$ respectively in the control group. When the gallstone group was compared with 11 subjects who had undergone cholecystectomy for gallstones there was a significantly higher percentage of deoxycholate radioactivity in the cholecystectomy group on each day. The mean values $( \pm S D)$ for each of the four days in the latter group were $24 \cdot 8 \pm 11 \cdot 7,52 \cdot 5 \pm 21 \cdot 3,64 \cdot 0 \pm 22 \cdot 0$, and $71.5 \pm 22.3$ respectively $(\mathrm{P}<0.05$ on day 1 , $P<0.025$ on days 2,3 , and 4 ).

\section{Discussion}

In this study we have confirmed the original finding of Vlahcevic et al (1970) that, in subjects with presumed cholesterol gallstones, the size of the total bile salt pool is reduced, due to reduction in the pools of both primary bile salts, cholate and chenodeoxy- cholate. However, unlike Vlahcevic et al we found a distinct overlap with control subjects. This may be because the American workers studied male subjects, whereas we studied females. As gallstones occur more often in women than in men, a female control group is more likely to contain subjects in a pregallstone state. American Indians believed to be in this state have been shown to have a small bile salt pool (Bell et al, 1972; Vlahcevic et al, 1972).

It has been widely accepted that reduction in the bile salt pool precedes the formation of gallstones and may be a factor in the secretion of lithogenic bile (Bouchier, 1971 ; Redinger and Small, 1972; Dowling, 1973). It is possible, however, that the bile salt pool is small because gallstones interfere with the storage function of the gallbladder, either by encroaching on its lumen, or by obstructing the cystic duct, or by being associated with disease of the gallbladder mucosa. Total loss of gallbladder storage is certainly associated with a reduced bile salt pool (Pomare and Heaton, 1973). This idea is opposed by two facts. (1) In the patients studied here, the gallstones occupied only a small proportion of the gallbladder, which filled and opacified normally on cholecystography. (2) The bile salt pool is small in American Indians believed to be in a pregallstone state. However, neither of these facts can be interpreted with complete confidence. First, the storage function of the gallbladder cannot be measured at the present time, and there are no grounds for assuming that this function is normal simply because the gallbladder has opacified with a cholecystographic contrast medium. Secondly, it has not yet been shown that individuals 


\begin{tabular}{|c|c|c|}
\hline & Cholecystectomy & Gallstones \\
\hline Cholate pool & Reduced significantly (by $57 \%$ ) & Reduced significantly (by $39 \%$ ) \\
\hline Chenodeoxycholate pool & $\begin{array}{l}\text { Reduced significantly (by } 70 \% \text { ) and to a } \\
\text { greater extent than the cholate pool }\end{array}$ & $\begin{array}{l}\text { Reduced significantly (by } 48 \% \text { ) and to a } \\
\text { greater extent than the cholate pool }\end{array}$ \\
\hline Deoxycholate pool & Unchanged & Unchanged \\
\hline Total bile salt pool & Reduced significantly (by $48 \%$ ) & Reduced significantly (by $37 \%$ ) \\
\hline Relative composition of bile salt pool & $\begin{array}{l}19 \% \text { more deoxycholate } \\
13 \% \text { less chenodeoxycholate } \\
6 \% \text { less cholate } \\
\text { (all significant) }\end{array}$ & $\begin{array}{l}7 \% \text { more deoxycholate } \\
6 \% \text { less chenodeoxycholate } \\
1 \% \text { less cholate } \\
\text { (but none significant) }\end{array}$ \\
\hline $\begin{array}{l}\text { Rate of dehydroxylation of taurocholate, ie, } \\
{ }^{14} \mathrm{C} \text { incorporated into deoxycholate conjugates }\end{array}$ & $\begin{array}{l}\text { Markedly and significantly increased on all } \\
4 \text { days (average } 104 \% \text { rise) }\end{array}$ & $\begin{array}{l}\text { Slightly higher on all } 4 \text { days, but } \\
\text { significantly so day } 1 \text { only (average } 33 \% \text { rise }\end{array}$ \\
\hline Half-life of taurocholate & Reduced significantly (by $41 \%$ ) & Reduced just significantly (by $30 \%$ ) \\
\hline Synthesis of taurocholate & Unchanged & Unchanged \\
\hline
\end{tabular}

Table A comparison of the main findings in cholecystectomy subjects and gallstone patients

with lithogenic bile and/or a small bile salt pool are predestined to the later development of gallst ones.

Our data indicate that, in gallstone patients, bile salt metabolism is changed in the same direction as it is after cholecystectomy but to a lesser extent. This is best shown by tabulating side by side the main findings in the two groups (table). The two parameters which were unchanged in cholecystectomy subjects (deoxycholate pool and taurocholate synthesis) were also unchanged in gallstone patients. Changes which were well marked in cholecystectomy subjects were always present though to a lesser degree in gallstone patients, for example, reduced primary bile salt pools, shortened taurocholate half-life, and increased dehydroxylation of taurocholate. As discussed in our earlier paper (Pomare and Heaton, 1973) all these changes are explicable by loss of gallbladder storage function.

These facts impel us to suggest that the storage capacity of the gallbladder is impaired in patients with gallstones, and that this impairment contributes to their small bile salt pool. It does not follow that the small pool is caused wholly by gallbladder dysfunction. Indeed, this seems unlikely since there is a substantial reduction in pool size but only a slight increase in bacterial dehydroxylation of taurocholate. In cholecystectomy subjects bacterial dehydroxylation was strikingly increased. It seems reasonable to deduce, therefore, that the small bile salt pool of gallstone disease has another and probably more important cause besides impaired gallbladder function. The present study throws no light on the nature of this other cause, but a number of considerations have led one of us to postulate refined carbohydrate in the diet as the major factor in the aetiology of cholesterol-rich gallstones (Heaton, 1972; Heaton, 1973).

Patients with pigment gallstones secrete normal bile unsaturated with cholesterol (Redinger and
Small, 1972). It would be helpful to have information on bile salt pool size in such patients. If this were found to be reduced as much as it is with cholesterol stones, this would throw grave doubt on the pathogenic significance of a small bile salt pool, and would suggest that it is simply caused by impaired gallbladder function.

It has recently been found that some patients with gallstones secrete bile which is, paradoxically, nonlithogenic (Mackay, Crook, Smith, and McAllister, 1972; Redinger and Small, 1972; Smallwood, Jablonski and Watts, 1972). It has also been shown that, for reasons as yet unknown, cholecystectomy 'improves' the lipid composition of bile, making it non-lithogenic (Shaffer, Braasch, and Small, 1972; Simmons, Ross, and Bouchier, 1972). Our present findings suggest a possible link between these two phenomena, namely, that those patients who secrete non-lithogenic bile have impaired gallbladder function and behave like cholecystectomy subjects.

We are grateful to Dr Susan T. Heaton for help with the assays, to Miss E. H. L. Duncan and Dr C. A. Pennock for statistical advice, and to $\operatorname{Dr} T$. S. Low-Beer for helpful discussions. The investigation was performed with the aid of a research grant from the United Bristol Hospitals and of a Commonwealth scholarship.

\section{References}

Bell, C. C. Jr., McCormick, W. C., II, Gregory, D. H., Law, D. H., Vlahcevic Z. R., and Swell, L. (1972). Relationship of bile acid pool size to the formation of lithogenous bile in male Indians of the Southwest. Surg. Gynec. Obstet., 134. 473-478.

Bell, C. C. Jr. Vlahcevic, Z. R., and Swell, L. (1971). Alterations in the lipids of human hepatic bile after the oral administration of bile salts. Surg. Gynec. Obstet., 132, 36-42.

Bouchier, I. A. D. (1971). Gallstone formation. Lancet, 1, 711-715.

Danzinger, R. G., Hofmann, A. F., Schoenfield, L. J., Berngruber, O. W., Szczepanik, P. A., and Klein, P. D. (1971). Measurement of bile acid kinetics in man using stable isotopes: application to cholelithiasis. (Abstr.). Gastroenterology, 60, 192.

Dowling, R. H. (1973). The dissolution of gallstones. In Proceedings of 
the Ninth Advanced Medicine Symposium, edited by J. G. Walker. Pitman, London.

Grundy, S. M., Metzger, A. L., and Adler, R. D. (1972). Mechanisms of lithogenic bile formation in American Indian women with cholesterol gallstones. J. clin. Invest., 51, 3026-3043.

Heaton, K. W. (1972). Bile Salts in Health and Disease. Churchill Livingstone, Edinburgh and London.

Heaton, K. W. (1973). Gallstone formation. In Proceedings of the Ninth Advanced Medicine Symposium, edited by J. G. Walker. Pitman, London.

Mackay, C., Crook, J. N., Smith, D. C., and McAllister, R. A. (1972). The composition of hepatic and gallbladder bile in patients with gallstones. Gut, 13, 759-762.

Pomare, E. W., and Heaton, K. W. (1973). The effect of cholecystectomy on bile salt metabolism. Gut, 14, 753-762.

Redinger, R. N., and Small, D. M. (1972). Bile composition, bile salt metabolism and gallstones. Arch. intern. Med., 130, 618-630.

Shaffer E. A., Braasch, J. W., and Small, D. M. (1972). Bile composi- tion at and after surgery in normal persons and patients with gallstones. New Engl. J. Med., 287, 1317-1322.

Simmons, F., Ross, A. P. J., and Bouchier, I. A. D. (1972). Alterations in hepatic bile composition after cholecystectomy. Gastroenterology, 63, 466-471.

Small, D. M. (1970). The formation of gallstones. Advanc. intern. Med., 16, 243-264.

Smallwood, R. A., Jablonski, P., and Watts, J. McK. (1972). Intermittent secretion of abnormal bile in patients with cholesterol gallstones. Brit. med. J., 4, 263-266.

Vlahcevic, Z. R., Bell, C. C., Jr., Buhac, I., Farrar, J. T., and Swell, L. (1970). Diminished bile acid pool size in patients with gallstones. Gastroenterology, 59, 165-173.

Vlahcevic, Z. R., Bell, C. C., Jr., Gregory, D. H., Buker, G. Juttijudata, P., and Swell, L. (1972). Relationship of bile acid pool size to the formation of lithogenic bile in female Indians of the Southwest. Gastroenterology, 62, 73-83. 